\title{
Drosophila MEF2, a transcription factor that is essential for myogenesis
}

\author{
Barbara A. Bour, ${ }^{1}$ Martha A. O'Brien, ${ }^{2}$ Wendy L. Lockwood ${ }^{3}$ Elliott S. Goldstein, ${ }^{4}$ Rolf Bodmer, ${ }^{3}$ \\ Paul H. Taghert, ${ }^{2}$ Susan M. Abmayr, ${ }^{1}$ and Hanh T. Nguyen ${ }^{5,6}$ \\ ${ }^{1}$ Department of Biochemistry and Molecular Biology, and Center for Gene Regulation, Pennsylvania State University, \\ University Park, Pennsylvania 16802 USA; $^{2}$ Department of Anatomy and Neurobiology, Washington University Medical \\ School, St. Louis, Missouri 63110 USA; ${ }^{3}$ Department of Biology, University of Michigan, Ann Arbor, Michigan 48109 USA; \\ ${ }^{4}$ Department of Zoology, Arizona State University, Tempe, Arizona 85287 USA; ${ }^{5}$ Department of Cardiology, Children's \\ Hospital, Boston, Massachusetts 02115 USA
}

mef2 encodes the only apparent Drosophila homolog of the vertebrate myocyte-specific enhancer factor 2 (MEF2). We show herein that the Drosophila MEF2 protein is expressed throughout the mesoderm following gastrulation. Later in embryogenesis, its expression is maintained in precursors and differentiated cells of the somatic and visceral musculature, as well as the heart. We have characterized genetic deficiencies and EMS-induced point mutations that result in complete loss of MEF2 protein in homozygous mutant embryos. These embryos exhibit a dramatic absence of myosin heavy chain (MHC)-expressing myoblasts and lack differentiated muscle fibers. Examination of earlier events of muscle development indicates that the specification and early differentiation of somatic muscle precursors are not affected because even-skipped-,

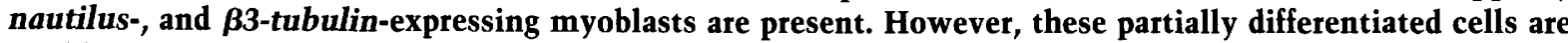
unable to undergo further differentiation to form muscle fibers in the absence of mef2. The later aspects of differentiation of the visceral mesoderm and the heart are also disrupted in mef2 mutant embryos, although the specification and early development of these tissues appear unaffected. Midgut morphogenesis is disrupted in the mutant embryos, presumably as a consequence of abnormal development of the visceral mesoderm. In the heart, the cardial cells do not express MHC. These results indicate that MEF2 is required for later aspects of differentiation of the three major types of musculature, which include body wall muscles, gut musculature, and the heart, in the Drosophila embryo.

[Key Words: Differentiation; Drosophila mef2; heart; myogenesis; somatic musculature; visceral mesoderm]

Received January 23, 1995; revised version accepted February 21, 1995.

Genes regulating the processes of determination and differentiation control cell-fate decisions that culminate in the progression of multipotential cells to distinct cell types. During Drosophila embryogenesis, the larval body wall musculature arises from morphologically indistinct mesodermal cells to an elaborate pattern of segmentally repeated muscle fibers over a period of $\sim 10 \mathrm{hr}$. Genetic and molecular studies have identified components of the myogenic pathway, which begins with specification of the mesoderm. The mesoderm is established by a morphogenetic gradient, in which the maternal Dorsal protein is selectively localized to nuclei on the ventral side of the embryo and activates subsequently the zygotic genes twist and snail (Roth et al. 1989; Rushlow et al. 1989; Steward 1989). These two genes are required for specification of the mesoderm and appear to regulate, either directly or indirectly, genes that are expressed ubiquitously in this germ layer (Kosman et al. 1991; Leptin 1991; see also references therein). The Drosophila

${ }^{6}$ Corresponding author. mef2 gene is one of the first genes to be activated shortly after twist expression in the presumptive mesoderm (Lilly et al. 1994; Nguyen et al. 1994). Other genes include the homeo box-containing genes tinman and $z f h-1$, as well as DFR1, the Drosophila homolog of fibroblast growth factor, and Drac1, a GTPase (Lai et al., 1991; Azpiazu and Frasch 1993; Bodmer 1993; Shishido et al. 1993; Luo et al. 1994).

The mesoderm epithelium separates into two layers $\sim 6 \mathrm{hr}$ after fertilization. The inner layer, in the dorsolateral position, contains the progenitors of the visceral musculature. tinman, which is initially expressed throughout the mesoderm and becomes restricted to the dorsal cells of the mesoderm at later stages, is essential for proper development of the visceral musculature and the heart (Azpiazu and Frasch 1993; Bodmer 1993). bagpipe, a homeo box-containing protein that is restricted to the primordia of the visceral mesoderm, is necessary for its formation and differentiation (Azpiazu and Frasch 1993). Additional genes, including $z f h-1$ and the homeo box-containing gene $H 2.0$, are also expressed in the inner 
mesodermal layer but their precise role remains unclear (Barad et al. 1991; Lai et al. 1993). The somatic musculature is specified by the cells in the outer mesodermal layer. Several genes have been identified that are expressed in cells of this layer, including apterous, S59, nautilus (nau)/Dmyd, even-skipped (eve), DFR1, and vestigial (Frasch et al. 1987; Dohrmann et al. 1990; Michelson et al. 1990; Paterson et al. 1991; Bourgouin et al. 1992; Bate et al. 1993; Shishido et al. 1993). These genes have expression profiles and, in some cases, mutant phenotypes that include distinct subsets of muscle precursors and differentiated muscle fibers.

$D$-mef2, hereafter designated as mef2, is expressed throughout the mesoderm following gastrulation (Lilly et al. 1994; Nguyen et al. 1994). The ubiquitous mef2 expression decreases during germ-band extension and later increases in somatic muscle precursors, visceral mesoderm, and heart precursors. By the completion of germ-band retraction, mef2 transcripts are abundantly expressed throughout the somatic musculature. The mef2 pattern of expression is in marked contrast to those of $e v e$ and nau, which appear to mark subsets of muscle precursors and differentiated muscle fibers.

mef2 encodes the only apparent Drosophila homolog of a family of vertebrate myogenic factors, termed MEF2 (myocyte-specific enhancer factor 2). The encoded proteins all contain the evolutionarily conserved MADS box-containing DNA-binding domain, as well as the MEF2-specific domain. MEF2-binding sites, conforming to the consensus sequence PyT(A/T)(A/T)AAATAPu, have been found in the upstream region of a number of muscle-specific genes, including MyoD and myogenin (Gossett et al. 1989; Wentworth et al. 1991; Edmonson et al. 1992; Nakatsuji et al. 1992; Navankasattusas et al. 1992; Tapscott et al. 1992). In some cases, these sites have been shown to be functionally important (Edmonson et al. 1992; Cheng et al. 1993; Yee and Rigby 1993).

To address the role of mef2 in vivo, we have characterized genetic mutations that result in the loss of mef2encoded protein. We show that these mef2 mutant embryos exhibit a dramatic absence of myosin heavy chain (MHC) expression in cells in positions of the somatic musculature and lack differentiated muscle fibers. Somatic muscle precursors that are present in the mef2 mutant embryos are specified but do not undergo full differentiation to multinucleate muscle fibers in the absence of mef2. We observe further that the early development of the visceral mesoderm and heart appears to be unaffected. However, midgut morphogenesis is disrupted and MHC expression is not detected in the heart at later stages of development.

\section{Results}

MEF2 protein is nuclear and present

in the progenitors of all three muscle types

Previous studies have established that mef2 RNA transcripts are detectable throughout the mesoderm during germ-band extension and later become restricted to the somatic and visceral muscles, as well as heart precursor cells in germ band-retracted embryos (Lilly et al. 1994; Nguyen et al. 1994). Here, we present immunocytochemical studies showing that MEF2 protein expression is also detected throughout the mesoderm during germband extension (Fig. 1A). After subdivision of the mesoderm, MEF2 expression is observed in the cephalic mesoderm and the primordia for visceral and somatic musculature (Fig. 1B). Throughout germ-band retraction and in older embryos, MEF2 expression persists in the visceral and pharyngeal musculature, as well as in cardial cells, the heart precursor cells that will form the heart muscle (Fig. 1C-E). In addition, its somatic expression is detected in segmentally repeating clusters of mesodermal cells that are in positions corresponding to groups of forming somatic muscles (Fig. 1E,F). Notably, MEF2 expression is restricted to muscle progenitors and it is not detected in fat body and pericardial cells. Moreover, MEF2 protein expression at all stages is localized to the nucleus, which is consistent with the fact that it is a transcription factor.

\section{Molecular characterization of mef2 null mutations}

To determine the function of mef2, we have focused on identifying and analyzing mef2 mutants. The cytological region $46 \mathrm{C}-\mathrm{D}$, the location of both FMRFamide and mef2 genes, was mutagenized previously $\left(\mathrm{O}^{\prime} \mathrm{Brien}\right.$ et al. 1994). Two X-ray induced deletions, $D f(2 R) X 1$ and $D f(2 R) X 3$, have been mapped to this region. As shown in Figure 2, the proximal breakpoints of $D f(2 R) X 1$ and $D f(2 R) X 3$ are located distal and proximal to the FMRFamide gene, respectively. In addition, $D f(2 R) P 520$, which was generated by mobilization of a P-element in this region, deletes $\sim 70 \mathrm{~kb}$ of the region surrounding the FMRFamide gene.

Southern blot analysis with DNA that was enriched for the mutant chromosomes (Bodmer 1993), indicated that $D f(2 R) X 3$ and $D f(2 R) P 520$ lack the mef2 gene and that $D f(2 R) X 1$ breaks within the mef2 gene itself (data not shown). To map the breakpoints of these deficiencies, we determined the structural organization of the mef2 gene. Detailed Southern blot analyses were performed with restriction fragments derived from cosmid and $\lambda$ genomic clones spanning this region (see Fig. 2). The intron-exon boundaries were then identified by targeted sequencing. As depicted in Figure 2, the mef2 gene spans $>14 \mathrm{~kb}$ and contains eight introns, the largest of which is $\sim 6 \mathrm{~kb}$ in length. Taken together, the information indicates that the proximal breakpoint of $D f(2 R) X 3$ is downstream of the mef2 gene, whereas that of $D f(2 R) X 1$ is within the large intron that interrupts its $5^{\prime}$-untranslated region. On the basis of the location of the breakpoints of $D f(2 R) P 520$, we conclude that trans-heterozygotes of $D f(2 R) X 1$ and $D f(2 R) P 520$ would carry a deletion of $\sim 12 \mathrm{~kb}$ that includes the mef2 gene locus.

Because the long stretch of DNA deleted in these trans-heterozygotes could include another gene, it was important to obtain point mutants that map to this region. A previous screen had identified several lethal 
Figure 1. MEF2 protein is nuclear and present in the precursors of all three muscle types. Wild-type embryos were stained with a rabbit polyclonal antibody against Drosophila MEF2 protein. The embryos are oriented with the anterior to the left [stages are according to Campos-Ortega and Hartenstein 1985|]. (A) Lateral view, stage 11 germ-band-extended embryo with MEF2 protein expression throughout the mesoderm $(\mathrm{m}) .(B)$ Lateral view, late stage 12 germ-band-retracting embryo. MEF2 expression is restricted to the visceral (vm) and somatic $(\mathrm{sm})$ mesodermal layers, and the cephalic mesoderm $(\mathrm{cm})$. $(C)$ Dorsal view, late stage 13 germ-band-retracted embryo showing MEF2 expression in the somatic $(\mathrm{sm})$ and visceral $(\mathrm{vm})$ mesoderm, and the pharyngeal musculature $(\mathrm{phm}) .(D)$ High magnification of an embryo at a slightly later stage than in $C$. Focus is on MEF2 expression in the somatic (sm) and visceral (vm) musculatures. (E) Dorsal view, stage 15 embryo. MEF2 expression is

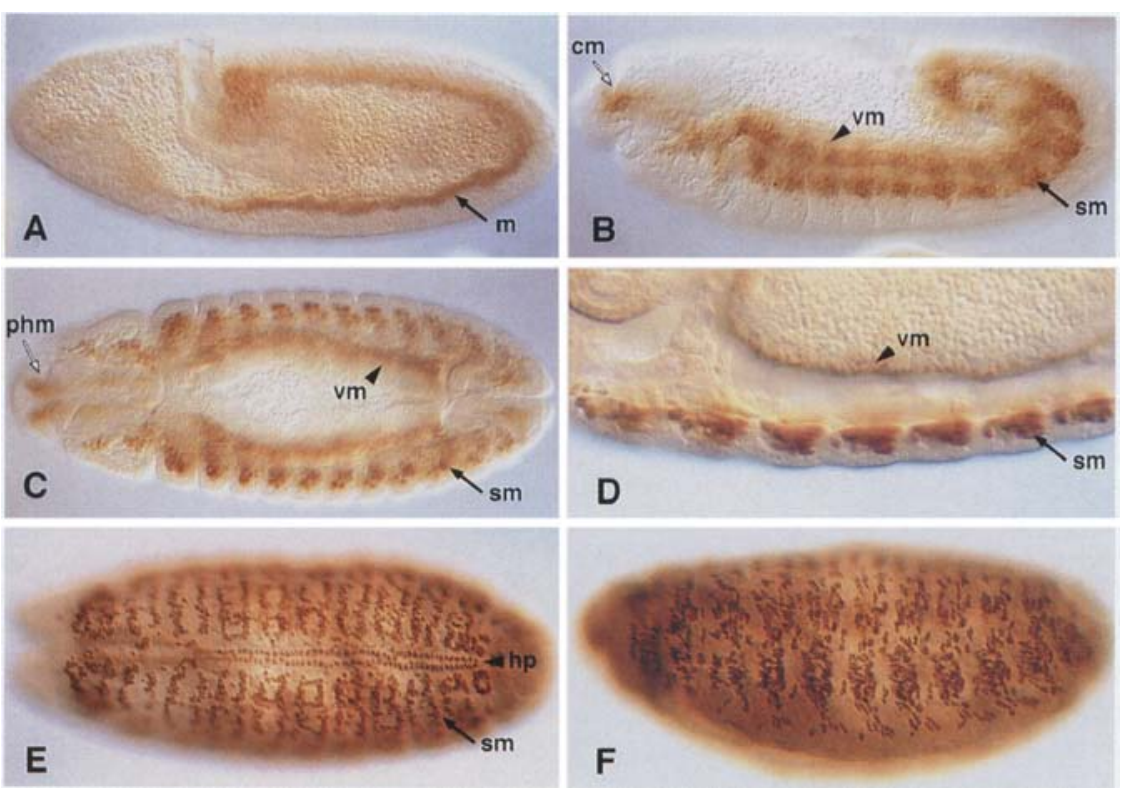
observed in repeating nuclear clusters of fused somatic mesodermal (sm) cells and two rows of heart precursor (hp) cells. $(F)$ Lateral view, stage 16 embryo. MEF2-positive clusters of nuclei in locations corresponding to syncytial fibers of differentiating somatic muscles.

complementation groups in this region (see Materials and methods). On the basis of the molecular characterization of mef2 sequences in the deficiencies described above, we anticipated that the desired mutations would be identified by lack of complementation to $D f(2 R) X 1$, $D f(2 R) X 3$, and $D f(2 R) P 520$. Ten lethal complementation groups were uncovered by $D f(2 R) X 1$ and $D f(2 R) X 3$ (see Table 1). Of these, only one, designated as group $C$, was unable to complement $D f(2 R) P 520$. A representative ethyl methane sulfonate (EMS)-induced allele from this group, designated as 22-21, was analyzed further for alterations in the mef2 gene sequence.

The presence of mef2-encoded protein was analyzed in EMS allele $22-21$ by use of the antibody directed against MEF2 (see Materials and methods). As shown in Figure 3, no MEF2 is observed in embryos bearing this mutation. To characterize the lesion molecularly, genomic DNA from homozygous mutant embryos was amplified by the polymerase chain reaction (PCR). The second and third exons, which include the MADS and MEF2-specific regions, were amplified from mutant genomic DNA, subcloned, and sequenced. The results from this analysis identified a base change that converts the sixth codon into a nonsense mutation (Fig. $3 \mathrm{C}$ ). Thus, we designate this allele as mef $2^{22-21}$ and conclude that it is a protein null lesion in mef2.

\section{Embryos lacking mef2 exhibit severe defects in myogenesis}

To determine the role of mef2 in Drosophila myogenesis, we examined the mutant phenotype of embryos that are lacking detectable MEF2 protein. Included in this study were embryos trans-heterozygous for the deficiencies $D f(2 R) X 1 / D f(2 R) P 520$, which is a MEF2 protein null combination (data not shown), and embryos trans-heterozygous for $m e f 2^{22-21} / D f(2 R) P 520$, the EMS-induced protein null mef2 allele and a deficiency. Both genetic combinations produce embryonic lethality. Somatic muscle development was initially visualized with a monoclonal antibody to Drosophila muscle-specific MHC. A comparison of wild-type and mutant embryos is shown in Figure 4. Whereas the wild-type embryo (Fig. 4A) exhibits an ordered array of muscle fibers, both trans-heterozygous combinations of mef2 mutant embryos (Fig. 4B-D) show an almost complete absence of MHC-expressing cells and lack muscle fibers. In addition, MHC expression is not observed in the pharyngeal musculature. Of note, a very limited number of elongated MHC-expressing cells are observed (see arrows in Fig. 4B,Cl. Although the exact nature of these cells is not clear, their presence suggests that a very small number of myoblasts are able to differentiate to some extent in the absence of MEF2.

\section{mef 2 sequences rescue aspects of the mutant phenotype}

To demonstrate that the loss of the mef2 gene is responsible for the mutant phenotype described above, we utilized the GAL4 system of Brand and Perrimon (1993) to provide restricted mef2 function in the mutant embryos. The mef2 cDNA was placed under the control of UAS GAL4-binding sites. The resulting construct, upstream 


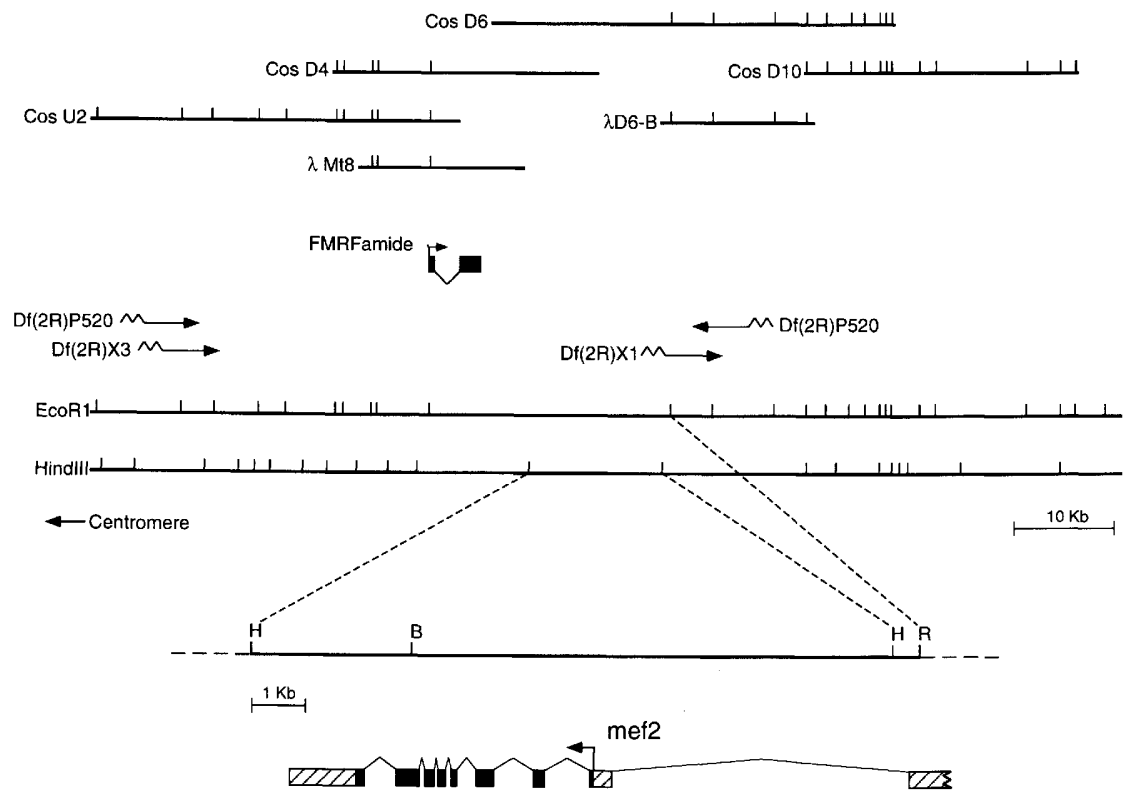

Figure 2. Molecular map of the $46 \mathrm{C}$ region surrounding the Drosophila mef2 and FMRFamide genes. Cosmid (Cos) and $\lambda$ genomic clones are shown above the HindIII and EcoRI restrictions maps. Deficiency breakpoints are denoted by a wavy line, and the direction of the deletion by an arrow. The region spanning the mef 2 gene has been expanded to illustrate its structural organization. The solid boxes correspond to exons; the hatched boxes correspond to untranslated regions. The start of translation is indicated by an arrow. activating sequence (UAS) - mef2, was transformed into Drosophila, as described in Materials and methods. The presence of the original mef2 mutation in the rescue strain was confirmed by lack of complementation of the $D f(2 R) P 520$ deficiency, as well as by the presence of mef2 mutant embryos in the progeny (data not shown). Furthermore, the presence of the UAS-mef 2 construct was confirmed by Southern analysis of DNA from a representative number of individual flies (data not shown).

To direct the expression of the UAS-mef2 construct, we used 24B, a line in which GAL4 expression is directed to muscle cells and a small number of cells in positions above the ventral ganglion of late stage embryos (Brand and Perrimon 1993). The 24B insertion was also crossed into a mef 2 mutant background and balanced over $\mathrm{CyO}$

Table 1. Complementation analysis between Df(2R)P520 and lethal allele mapped to the 46C-E region

\begin{tabular}{lccc}
\hline Group & $\begin{array}{l}\text { Allele } \\
\text { no. }\end{array}$ & $\begin{array}{l}\text { Trans-heterozygotes } \\
\text { total progeny }\end{array}$ & $\begin{array}{l}\text { Percent } \\
\text { trans-heterozygotes }\end{array}$ \\
\hline C $^{\text {c }}$ & $22-21$ & $0 / 106$ & 0 \\
E & $5-3$ & $20 / 89$ & 22 \\
F & $10-9$ & $38 / 95$ & 40 \\
F & $14-10$ & $41 / 157$ & 26 \\
I & $7-12$ & $32 / 107$ & 30 \\
M & $7-5$ & $31 / 109$ & 28 \\
O & $20-10$ & $41 / 89$ & 46 \\
Q & $26-19$ & $30 / 100$ & 30 \\
T & $68-11$ & $27 / 87$ & 32 \\
U & $78-10$ & $32 / 121$ & 26 \\
X & $97-16$ & $28 / 76$ & 37 \\
\hline
\end{tabular}

${ }^{a}$ Mutant/Df(2R)P520.

bexpected frequency of trans-heterozygotes is $33 \%$.

'This $\mathrm{C}$ designation does not correspond to the $\mathrm{C}$ group in O'Brien et al. (1994). that is marked with $\beta$-galactosidase (see Materials and methods). The presence of a mef2 mutation in the final stock and the presence of the GAL4 construct were confirmed, as above (data not shown).

The appropriate Drosophila lines described above were mated to express MEF2 in a mef2 mutant background. The progeny of this cross exhibited GAL4-directed mef2 expression in the muscle cells, as well as in cells over the ventral ganglion of late stage embryos, where endogenous mef2 expression is not normally observed. Included in the progeny of this cross are trans-heterozyous rescued mutant embryos that are identifiable by the absence of $\beta$-galactosidase staining (see Materials and methods). As shown in Figure 5A, these embryos exhibit significant levels of MEF2 protein expression.

We visualized the muscle pattern of the rescued mutant embryos with an antibody that recognizes Drosophila muscle-specific MHC protein. A representative rescued embryo is shown in Figure $5 \mathrm{~B}-\mathrm{C}$. By comparison to the embryos shown in Figure $4 \mathrm{~B}-\mathrm{D}$, these embryos now exhibit significant muscle fiber formation. Moreover, these muscles appear to be remarkably normal with respect to location and attachment. mef2 expression under the control of the 24B-GAL4 line is, however, not sufficient to rescue viability because these embryos do not hatch into larvae. In addition, a significant number of unfused myoblasts are found among the MHCexpressing cells in the rescued embryos /see arrows in Fig. $5 \mathrm{Cl}$. These observations suggest that regulatory sequences present in the mef2 gene are needed to obtain full rescue. Nevertheless, this artificial means of providing exogenous MEF2 protein does result in the recovery of muscle fibers in embryos trans-heterozygous for $m e f 2^{22-21} / D f(2 R) P 520 ; 24 B-G A L 4 / U A S-m e f 2$ (Fig. $5 B, C)$. In summary, our data demonstrate that muscle fibers do not form in the absence of mef2. This defect can be rescued by providing exogenous MEF2 in the somatic 


\section{Bour et al.}

Figure 3. $m e f 2^{22-21}$ is a protein null allele. Heterozygous and homozygous mef $2^{22-21}$ mutant embyos were doubly stained with a rabbit polyclonal antibody against MEF2 and a mouse monoclonal antibody against $\beta$-gal. The embryos are oriented with the anterior to the left and the ventral facing downward. (A) The heterozygous embryo shows MEF2 expression in the somatic (arrow) and visceral (solid arrowhead) mesoderm. Because the nonmutant chromosome was marked with a $\mathrm{P}[$ IacZ] [see Materials and methods), the heterozygous embryo also shows LacZ expression (open arrowhead). $(B)$ There is no detectable MEF2 protein in the somatic (arrow) or visceral (arrowhead) mesoderm in the homozygous embryo. $(C)$ The exons spanning

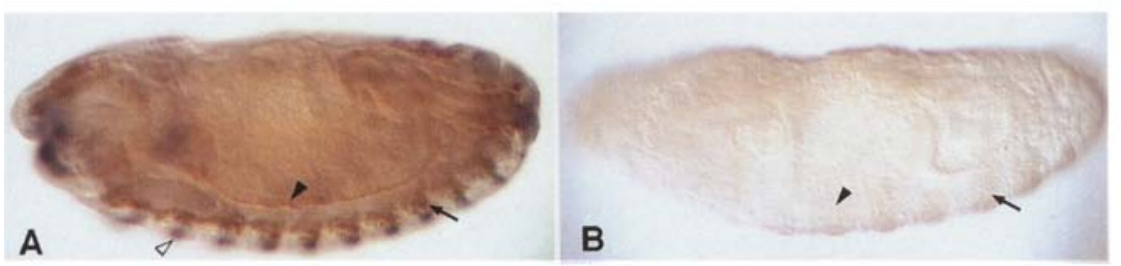

C

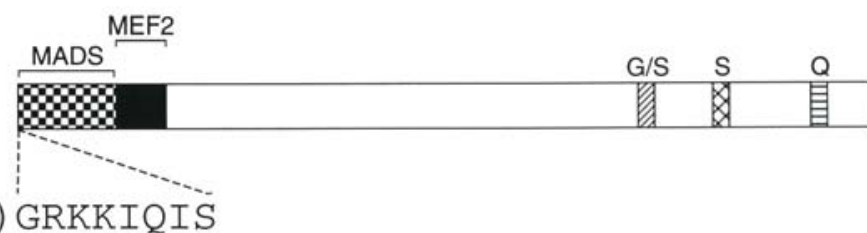

Wt (M) GRKKIQIS

mef2 $^{22-21}$ (M) GRKKIstop the MADS-MEF2 region were amplified from genomic mutant DNA by use of the PCR, subcloned, and sequenced. The mutation was identified as being a base change that converted the sixth codon into a nonsense codon. This is depicted in an expanded form below the schematic diagram of the MEF2 protein. G/S, S, and Q denote amino acid repeats (Nguyen et al. 1994).

mesoderm, thereby indicating that mef2 function is essential for myogenesis.

\section{Partially differentiated myoblasts are present in mef 2 mutant embryos}

MHC expression and multinucleate muscle fiber formation are relatively late aspects of myogenesis. Therefore, it was of interest to assess the extent of myogenesis in the mef2 mutant embryos at earlier developmental stages. To study these events, we examined the expres- sion of three additional markers, eve, nau, and $\beta 3-t u b u$ lin.

eve encodes a homeo box-containing factor that has been detected during germ-band retraction in precursor cells of one dorsal somatic muscle, which appears beneath the dorsal ectoderm in each hemisegment (Frasch et al. 1987; Bodmer 1993). eve also marks a small subset of pericardial cells of the dorsal vessel (discussed below) (Azpiazu and Frasch 1993; Bodmer 1993). nau encodes a basic-helix-loop-helix (b-HLH) domain-containing factor that is expressed in the nucleus in a subset of muscle precursor cells beginning at late germ-band extension

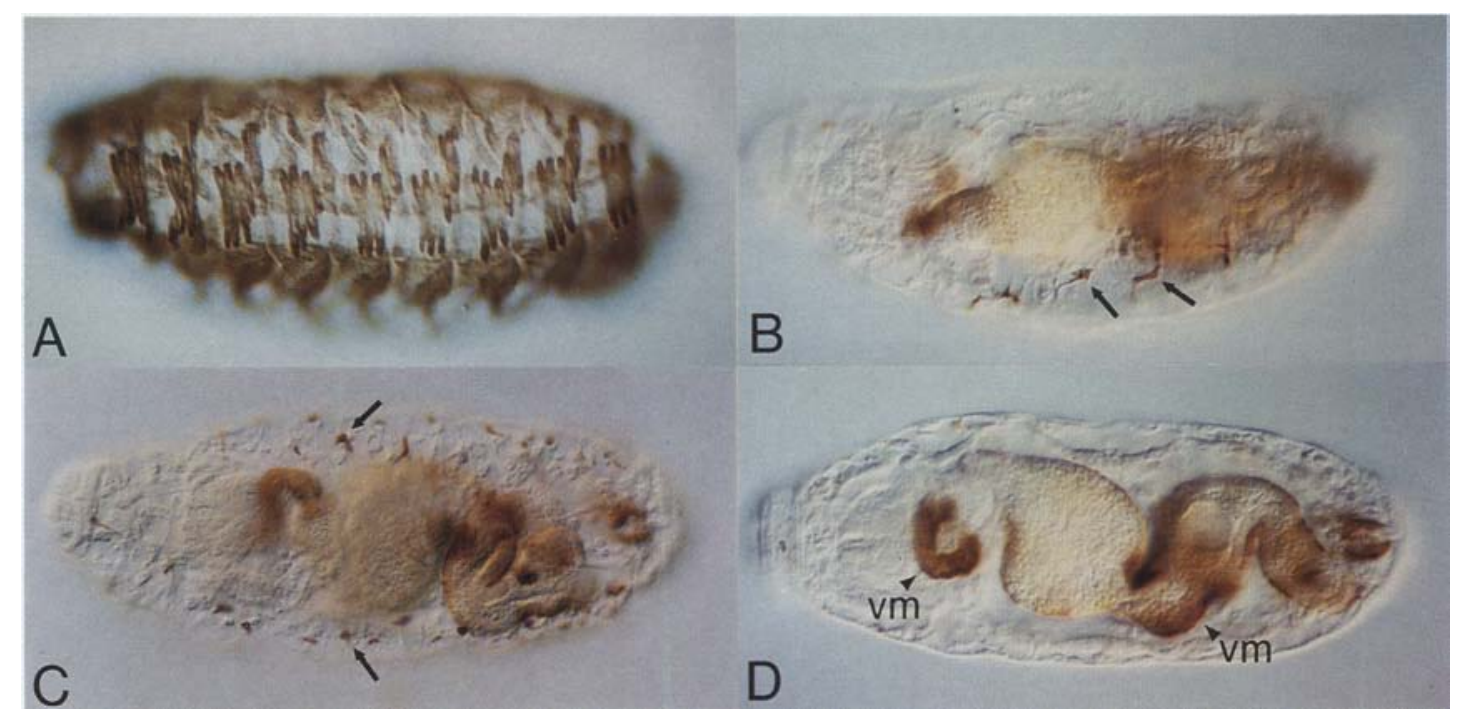

Figure 4. MHC expression in wild-type and mef2 mutant embryos. Embryos were analyzed with a monoclonal antibody against MHC (see Materials and methods). The embryos are oriented with the anterior to the left. (A) Wild-type, stage 16, lateral view. $(B)$ mef2 $22-21 / D f(2 R) P 520$ trans-heterozygote, stage 15 , lateral view. (C) $D f(2 R) X 1 / D f(2 R) P 520$ trans-heterozygote, stage 15 , dorsal view. $(D)$ mef $2^{22-21} / D f(2 R) P 520$ trans-heterozygote, stage 15 , ventral view. Arrows denote MHC-expressing cells in positions corresponding to that of the somatic musculature (sm). Arrowheads show MHC-expressing cells in the visceral musculature (vm). 


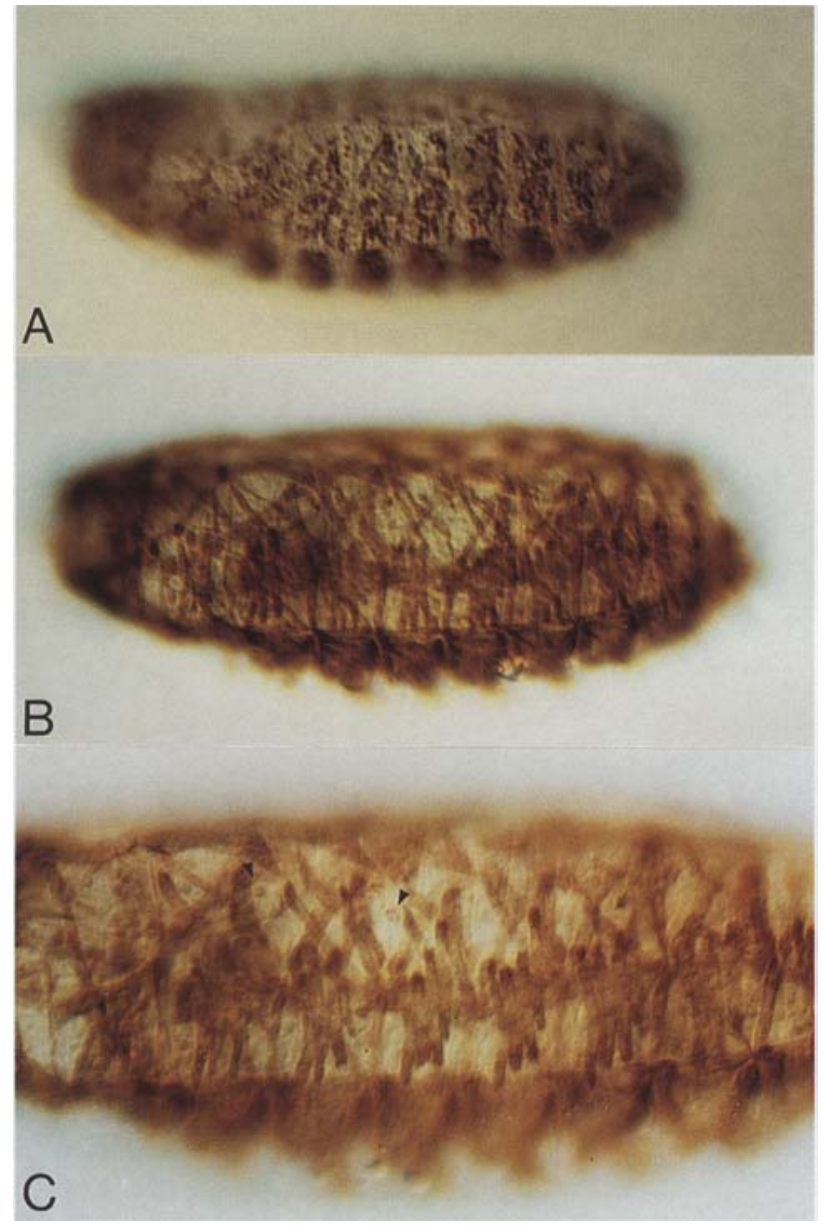

Figure 5. Rescued embryos exhibit MHC and MEF2 expression. Embryos were analyzed as in Fig. 4, with either a rabbit polyclonal antibody against $\operatorname{MEF} 2(A)$ or a mouse monoclonal antibody against $\mathrm{MHC}(B, C)$. The embryos are oriented with the anterior to the left. (A) mef2 $22-21 / D f(2 R) P 520 ; 24 B / U A S$ mef2 trans-heterozygote, stage 15 , lateral view. $(B)$ mef2 $2^{22-21}$, $D f(2 R) P 520 ; 24 B / U A S-m e f 2$ trans-heterozygote, stage 15 , lateral view. $(C)$ High magnification view of embryo shown in $B$. Arrowheads in $C$ indicate unfused myoblasts alongside and just underneath the somatic musculature.

and can be followed into distinct differentiated muscle fibers (Michelson et al. 1990; Paterson et al. 1991). Therefore, the products of these two genes serve as markers for subsets of the differentiating somatic mesoderm and can be followed through the transition from muscle precursors into muscle fibers.

As shown in Figure 6, both EVE- and NAU-expressing cells are readily apparent in the mutant embryos, indicating that mef2 is not necessary for the initial cell fate determination of these populations of myoblasts. In wild-type embryos, the EVE-positive dorsal nuclei become more numerous as muscle fiber formation progresses (Fig. 6A). In mef2 mutant embryos, however, only one mononucleate EVE-positive cell is detected per segment instead of several EVE-positive nuclei (Fig. 6B). Similar to EVE, NAU-expressing cells are observed in appropriate positions in mef2 mutant embryos (Fig. 6D). However, these mutant embryos do not exhibit NAUexpressing multinucleate syncytia, which are detected in wild-type embryos at the same developmental stage (Fig. $6 \mathrm{C})$. These observations indicate that although mef2 is not necessary for the initial specification of these muscle precursors, it is essential for the continued differentiation of the EVE- and NAU-positive somatic muscle precursors to form typical muscle fibers.

In contrast to EVE and NAU, which mark specific subsets of muscle precursors, $\beta 3$-Tubulin serves as a marker for the entire myoblast population. In wild-type embryos, it is expressed in all somatic mesoderm during germ-band extension (Leiss et al. 1988), several hours before MHC expression at late germ-band retraction (Bernstein et al. 1993), and can be followed into all somatic muscle fibers (Fig. 6E). A large number of $\beta 3-\mathrm{Tu}-$ bulin-expressing myoblasts are evident in mef2 mutant embryos (Fig. 6F), indicating that the bulk of the myoblast population has been specified and exhibits early aspects of myogenesis. However, as compared with similarly staged wild-type embryos (Fig. 6E), the vast majority of mef2 mutant $\beta 3$-Tubulin-expressing myoblasts are unfused and are unable to activate the expression of MHC. Therefore, mef2 is not required for the initial cell fate determination of the general myoblast population but it is essential for its continued differentiation.

We explored the possibility that the partially differentiated mononucleate myoblasts present in the mef2 mutant embryos might undergo programmed cell death. We used the vital stain acridine orange to assay for cells undergoing programmed cell death (Abrams et al. 1993; White et al. 1994). There are moderate levels of cell death in various parts of wild-type embryos before the muscle fibers are fully formed (Abrams et al. 1993). After dorsal closure, when the muscle fibers have formed, significant levels of cell death occur only in the CNS (Fig. 6G). In contrast, there is an increase in cell death in the cell layer of the mesoderm in mef2 mutant embryos of the corresponding developmental stages (Fig. $6 \mathrm{H}$ ). We do not see an obvious increase in cell death in the region of the heart or visceral mesoderm (data not shown).

Taken together, the data indicate that the somatic mesoderm is formed normally and that somatic muscle precursor cells express markers of all ( $\beta 3$-Tubulin) or subsets (NAU and EVE) of somatic muscles in the absence of mef 2 function. However, the continuing differentiation of these somatic muscle precursors into multinucleate muscle fibers requires mef2 function.

\section{Mutant embryos lacking mef2 also exhibit abnormalities in the visceral musculature and the heart}

In contrast to the somatic musculature, a significant number of MHC-expressing cells surround the foregut and hindgut of mef2 mutant embryos (see Fig. 4B-D). Lowered, but detectable levels of MHC are also observed in a thin layer around the midgut. Because it has been established that morphogenesis of the midgut requires 


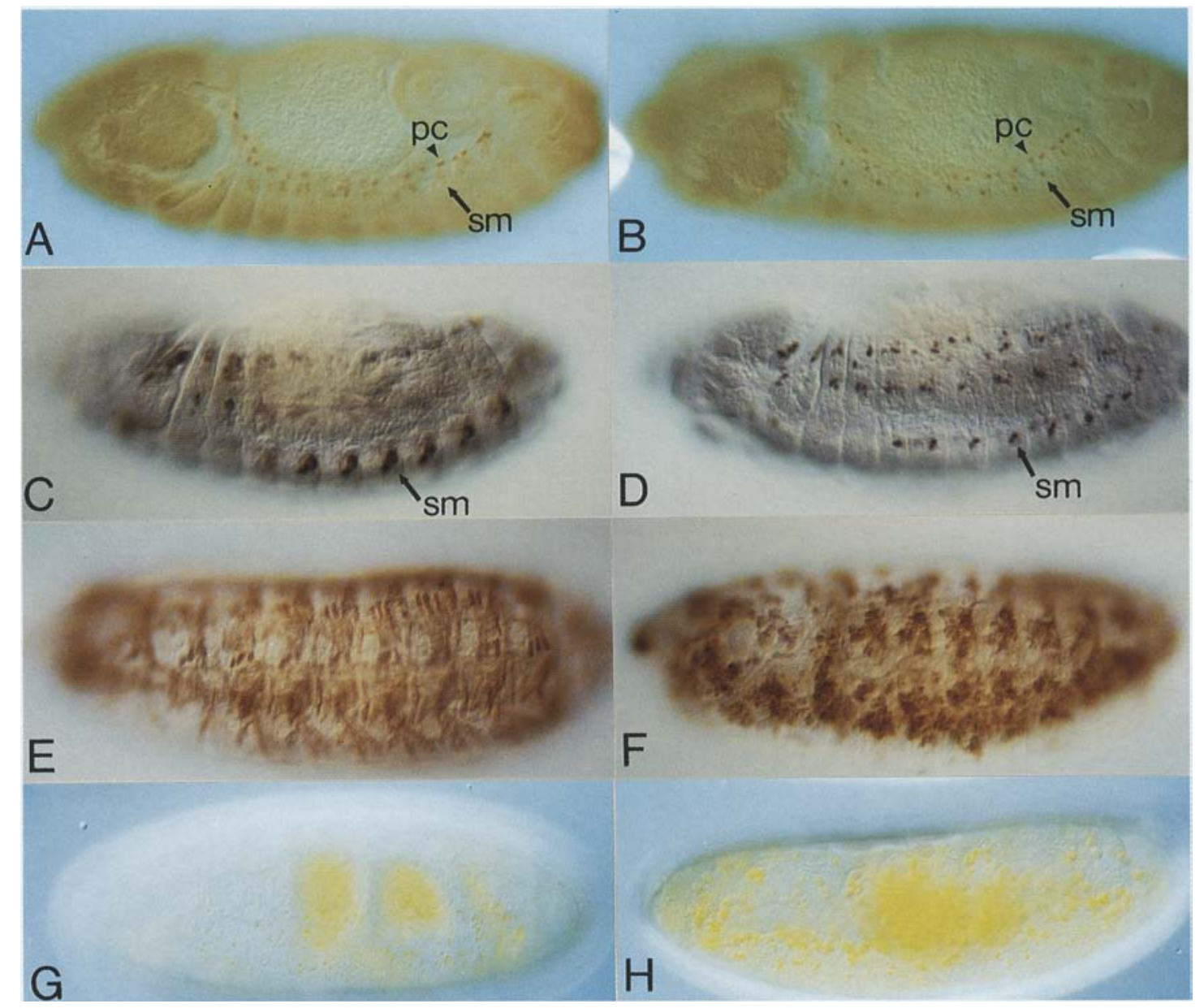

Figure 6. mef2 mutant embryos express mesodermal markers and exhibit increased cell death in the mesoderm at later stages. Embryos were analyzed with a rabbit polyclonal antibody against EVE $|A, B|$, a rat polyclonal against NAU $(C, D)$, or a rabbit polyclonal against $\beta 3$-Tubulin $(E, F)$. In $G$ and $H$, the embryos were analyzed by use of the vital dye acridine orange. In all views, the anterior is to the left. $(A)$ Wild-type, stage 13, dorsolateral view. $(B) D f(2 R) X 1 / D f(2 R) P 520$ trans-heterozygote, stage 13 , dorsolateral view. EVE-positive pericardial cells (pc) are denoted by arrowheads. EVE-positive nuclei in dorsal muscle precursors (sm) are highlighted by arrows. $(C)$ Wild-type, stage 13 , lateral view. $(D)$ mef $2^{22-21} / D f(2 R) P 520$ trans-heterozygote, stage 13 , lateral view. $(E)$ Wild-type, stage 14 , lateral view. $(F)$ mef2 $22-21 / D f(2 R) P 520$ trans-heterozygote, stage 14 , lateral view. Arrows highlight fused $(C)$ and unfused $(D)$ NAU-expressing cells. $(G)$ Wild-type, stage 15 , lateral view. $(H)$ mef $2^{22-21} / D f(2 R) P 520$ trans-heterozygote, stage 15 , lateral view.

the presence of visceral mesoderm (Reuter and Scott 1990; Azpiazu and Frasch 1993; Bodmer 1993), we determined whether mef2 could have a function in this process. In embryos lacking mef2, the morphology of the visceral mesoderm appears normal and midgut formation appears to proceed correctly in the early stages. We monitored visceral mesoderm formation by first examining the expression of fasciclin III (FASIII) (Patel et al. 1989 |. During germ-band retraction, FASIII expression in the visceral mesoderm of mef2 mutant embryos appears indistinguishable from wild-type embryos (data not shown). $\beta 3$-Tubulin expression in the visceral mesoderm also appears normal in mutant embryos (data not shown). However, the formation of constrictions and looping of the midgut at later stages are abnormal (Fig. $7 \mathrm{~A}, \mathrm{~B}$. Partial rescue of the gut contriction abnormality is observed in response to mef2 expression under the control of the 24B-GAL4 line (data not shown). These observations support the possibility that midgut morphogenesis, a late-occurring aspect of visceral mesoderm differentiation, is affected in mef2 mutants.

Because mef 2 is expressed in cardial cells, we examined a possible requirement of mef2 function for heart formation. In mef2 mutant embryos, cardial cells are present and express high levels of $\beta 3$-Tubulin (Fig. $7 \mathrm{C}$ ); however, MHC expression is not detectable in these cells (data not shown). The formation of the cardial cells is, therefore, not affected by the absence of mef2. We next examined the pericardial cells that are also mesodermally derived heart precursors. As mentioned previously, EVE expression in the pericardial cells of mef2 mutant embryos remains unchanged (see Fig. 6A,B). For further assessment, we used a monoclonal antibody that recognizes a cell-surface protein on pericardial cells of 


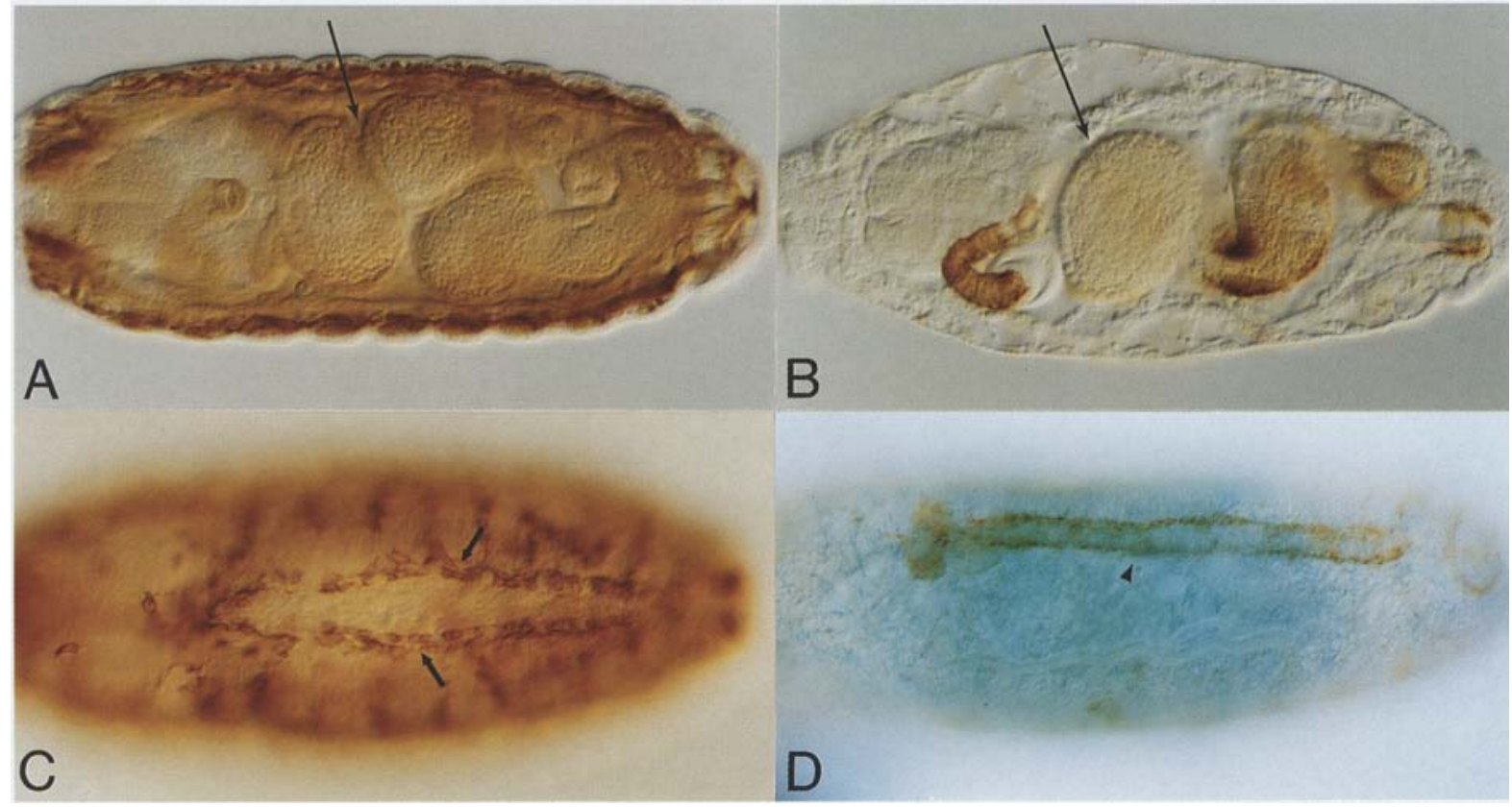

Figure 7. Visceral mesoderm and heart formation in mef2 mutants. Embryos were analyzed with a mouse monoclonal antibody against $\mathrm{MHC}(A, B)$, a rabbit antibody against $\beta 3$-Tubulin $(C)$ or a mouse monoclonal antibody against an epitope on pericardial cells (see Material and methods). $(D)$ In all views, the anterior is to the left. $(A)$ Wild-type, stage 16 , dorsal view. $(B)$ mef2 $2^{22-21} / D f(2 R) P 520$ trans-heterozygote, stage 16, dorsal view. Arrows highlight the abnormal constriction observed in the mutant embryo. $(C)$ mef $2^{22-21} /$ $D f(2 R) P 520$ trans-heterozygote, stage 16 , dorsal view. The cardial cells are indicated by arrows. $(D)$ mef2 $22-21 / D f(2 R) P 520$ transheterozygote, stage 16, dorsolateral view. The pericardial cells are indicated by arrowheads.

the heart (T. Volk, unpubl.). As observed with EVE, the pericardial cells that are stained with this monoclonal antibody appear normal (Fig. 7D). On the basis of this analysis, it appears that mef2 is not essential for early heart formation. However, it is required for later differentiation of the heart cells because these cells do not express MHC in the absence of mef2. Notably, MHC expression is detected in the cardial cells of rescued embryos, in response to mef2 expression under the control of the 24B-GAL4 line (data not shown).

\section{Discussion}

mef2 functions

We have presented evidence demonstrating that mef2 function is essential for myogenesis. Embryos lacking mef2 exhibit a striking absence of MHC-expressing cells in the position of the somatic musculature and do not develop differentiated muscle fibers. This role in mesodermal differentiation is consistent with the spatial and temporal profiles of mef2 mRNA and protein expression (Lilly et al. 1994; Nguyen et al. 1994; also Fig. 1). Aspects of the observed mutant phenotype can be rescued by providing exogenous mef2 gene activity in the mesoderm, by use of the GAL4 system of Brand and Perrimon (1993).

To define the mef2 mutant phenotype more precisely, we have examined the expression of markers for specific aspects of mesoderm differentiation. We show that NAU-, EVE-, and $\beta 3$-Tubulin-expressing myoblasts are present in the somatic musculature. These observations indicate that mef2 gene activity is not needed for the initial cell fate specification of these myoblasts. Rather, mef2 affects the continuing development of cells that have already undergone some aspects of myogenic specification. More specifically, mef2 is essential for subsequent activation of muscle-specific structural genes such as $\mathrm{MHC}$, and the progression to multinucleate muscle syncytia.

The first morphological signs of myogenesis in the Drosophila embryo are binucleate and trinucleate cells, termed muscle precursors, that form in close proximity to the ectoderm (Bate 1990). These muscle precursors occur in reproducible positions that prefigure the final muscle pattern. Such morphological observations have lead to the idea that muscles are formed by the fusion of a single mononucleate founder cell, which is responsible for the unique identity of each muscle fiber, with unspecified fusion-competent cells (Bate 1990). It has been postulated further that the identity of individual founder cells is determined by genes, such as 559 , which are expressed in a distinct subset of muscle precursors and differentiated fibers. As fusion proceeds, the identity of the founder cells would be conveyed to the cells that are recruited by fusion, and they, in turn, would activate expression of genes such as $S 59$ (Dohrmann et al. 1990). 
By analogy, one might anticipate that NAU and EVE proteins, which are also expressed in subsets of muscle precursors and differentiated muscle fibers, may specify some of the hypothetical founder cells. Within the context of this model, our results would suggest that the initial specification of founder cells does not require mef2. By comparison, $\beta 3$-Tubulin is expressed in many, if not all of the presumptive myoblasts, and would therefore be expressed in the hypothetical fusion-competent cells. Our results would also suggest that the initial specification of these cells does not require mef2. We do not know whether mef2 is expressed in all cells, including those that express NAU and EVE or whether it is restricted to the hypothetical fusion-competent cells. Whether mef2 is needed for the differentiation of just one, or both, of these cell types remains to be determined.

Increased numbers of dying cells were observed in the mesodermal layer that corresponds to the somatic musculature in mef2 mutant embryos. Interestingly, previous studies have shown that mutations disrupting cellular differentiation result in the death of those cells that are unable to complete the differentiation process (Smouse and Perrimon 1990; Tepass et al. 1990; Abrams et al. 1993; Bonini et al. 1993). Thus, our findings suggest that the partially differentiated somatic precursor cells present in these mutant embryos are subject to programmed cell death as a consequence of their failure to undergo complete differentiation.

In contrast to tinman and bagpipe (Azpiazu and Frasch 1993; Bodmer 1993), mef2 activity is required neither for the formation nor for the specification of the visceral mesoderm. On the basis of the observation that the midgut constrictions are abnormal in the absence of mef2, we suggest that it is required for later events in the differentiation of this tissue. Likewise, the formation of the cardial and pericardial cells do not appear to be affected in mef2 mutant embryos. However, the cardial cells in the mutant embryos express $\beta 3$-Tubulin but not MHC. This observation raises the possibility that mef2 function is needed in later aspects of differentiation, including activation of genes that are necessary for generating a functional heart. It is not known whether this function could involve interactions with tinman, which has been shown to be required for the formation of the heart, and like MEF2, is expressed in cardial cells of late stage embryos (Azpiazu and Frasch 1993; Bodmer 1993).

\section{Comparisons between mef2/MEF2 and nau/MyoD gene families}

It has been established that activation of skeletal muscle gene expression in vertebrates is regulated by the $\mathrm{MyoD}$ gene family, which encodes muscle-specific transcription factors sharing a common b-HLH motif (for review, see Weintraub 1993; Lassar and Munsterberg 1994; Olson and Klein 1994). Recent gene knockout studies have shown that unique, as well as overlapping functions, can be ascribed to these myogenic b-HLH factors (Braun et al. 1992; Rudnicki et al. 1992, 1993; Hasty et al. 1993;
Nabeshima et al. 1993). More recently, the myogenic MEF2 gene products have been implicated in the regulation of gene expression in both skeletal and cardiac muscles. DNA-binding activities that are attributable to the MEF2 transcription factors are restricted to all muscles (skeletal, cardiac, smooth muscle) and the brain (for review, see Lassar and Munsterberg 1994; see also references therein). The expression profiles of the MEF2 gene products during murine embryogenesis (Edmonson et al. 1994) and the functional importance of MEF2-binding sites have given further support for the proposed regulatory function of MEF2 (Edmonson et al. 1992; Cheng et al. 1993; Yee and Rigby 1993). However, confirmation must await the analysis of MEF2 mutant mice.

Previous and current studies on the Drosophila mef2 gene are providing insight into the potential role of the MEF2 gene family. Interestingly, the phenotype of the mef2 mutants is very reminiscent of that of mice lacking myogenin. Myogenin-deficient mice die perinatally and exhibit severe skeletal muscle defects (Hasty et al. 1993; Nabeshima et al. 1993|. Notably, severely disorganized myotubes or mononucleated myoblasts are found in the limbs of the mutant mice (Hasty et al. 1993; Nabeshima et al. 1993). As we have interpreted the mef2 phenotype, the myogenin phenotype suggests that it is also needed for the terminal differentiation of myoblasts to myotubes and not for the determination of skeletal myoblasts. Roles in myoblast determination have been ascribed to MyoD and Myf-5 (Rudnicki et al. 1994).

The hierarchical relationship between the vertebrate MEF2 and myogenic b-HLH gene members is not clear. Cell culture studies have suggested that the myogenic b-HLH genes are upstream of the MEF2 genes (Cserjesi et al. 1991; Martin et al. 1993), whereas in vivo studies indicate that MEF2 is required for proper regulation of myogenin gene expression (Cheng et al. 1993; Yee and Rigby 1993). More recent studies show that MEF2 induces the expression of MyoD and myogenin (Kaushal et al. 1994). In Drosophila, the relationship is more clear. mef2 expression is detected prior to the onset of nau expression and is observed in genetic deficiency lines that remove several genes, including nau (M. Erickson and S. Abmayr, unpubl.). Thus, nau does not appear to play a role in the activation of mef2. Likewise, our present data indicate that the initiation of NAU expression does not require mef2-encoded protein, because NAU-expressing cells are observed in appropriate positions in its absence. Because the temporal appearance of NAU-expressing cells is comparable to that observed in a wild-type embryo, and these cells continue to express significant levels of NAU for several hours, it appears that mef2 does not play a major role in the maintenance of NAU expression.

Initial mef2 expression is detected soon after twist expression and also depends on twist activity (Lilly et al. 1994; Nguyen et al. 1994). Although the observed mef2 mutant phenotype does not suggest an obvious function for the early mef2 expression in the undifferentiated mesodermal mass, our present data cannot rule out the possibility that this early function could be compensated by 
other mesodermal gene(s), including tinman and $z f h-1$. To further our understanding of the role of mef2 in mesoderm differentiation, it will be important to identify the target genes of mef2, some of which could be musclespecific genes that are common between Drosophila and vertebrates. It will also be interesting to determine whether the activation of some of these targets would require interactions with one or more mesodermal gene products. Recent studies have shown that mammalian MEF2 gene products can interact with b-HLH factors, such as myogenin and MyoD (Funk and Wright 1992; Kaushal et al. 1994).

\section{Material and methods}

Drosophila stocks

Fly stocks were raised at $18^{\circ} \mathrm{C}$ or $25^{\circ} \mathrm{C}$ on standard media. The following three deficiency stocks were used for identifying mef2 mutants: $D f(2 R) X 1 / C y O ; A d h^{n b}, D f(2 R) X 3 / C y O ; A d h^{n b}$, and $D f(2 R) P 520 / S M 6$ (O'Brien et al. 1994). In a screen for specific mutations in the $46 \mathrm{C}-\mathrm{F}$ region, flies were mutagenized with EMS, diepoxybutane (DEB) or $\gamma$-rays, and tested for lethality that is uncovered by $D f(2 R) X 1$ in a standard $F_{2}$ screen. EMS mutagenesis yielded 74 lethals from $\sim 15,000$ progeny, DEB yielded 21 lethals from $\sim 18,000$ progeny, and $\gamma$-rays yielded 31 lethals from $\sim 24,000$ progeny. Lethal alleles were then tested for lethality that is uncovered by $D f(2 R) X 3$. Flies with mutations mapping to the overlapping region of $D f(2 R) X 1-D f(2 R) X 3$ were tested further by crossing to $D f(2 R) P 520$.

For phenotypic studies, mutant stocks were balanced over CyO marked with $\left.\mathrm{P}\left[\mathrm{w}^{+}\right] a c Z\right]$ (obtained from H. Bellen, Baylor College of Medicine, Houston, TX|, resulting in the detection of $\beta$-gal expression in the anterior and posterior ends of the embryo, or wgen11 (obtained from N. Perrimon, Harvard Medical School, Boston, MA), which yields $\beta$-gal expression in the pattern of wg (Kassis et al. 1992). Balancer stocks used for generating the genetic combinations in the rescue experiments included TM3, Ser/TM6B, Hu P $\left[\mathrm{W}^{+} l a c Z\right]$ and yw; Pin/ $\mathrm{CyO}, \mathrm{P}\left[\mathrm{w}^{+}\right.$lacZ].

\section{Generation of UAS-mef2 strains and mef2 rescue stocks}

To create the UAS-mef2 rescue construct, a 3.0-kb EcoRIHindIII fragment of the D-mef2 cDNA (Nguyen et al. 1994), which includes the entire coding sequence, was subcloned into pBSKII (Stratagene). This plasmid was digested with $\mathrm{XbaI}$ and $X$ hoI and the resulting fragment was subcloned into the vector pUAST (Brand and Perrimon 1993). Transgenic lines containing the UAS-mef2 construct were generated by injection of $\mathrm{yw}^{-}$ embryos, according to published procedures (Rubin and Spradling 1982; Spradling and Rubin 1982). Eight independent transformant lines were obtained and expanded into homogeneous stocks (either homozygous or balanced, as appropriate).

The GAL4-expressing enhancer trap line $24 B$ (Brand and Perrimon 1993) was generously provided by N. Perrimon. The $U A S-m e f 2$ stock is described above. Stocks homozygous for either $24 B$ or $U A S-m e f 2$, both located on the third chromosome, were crossed into various mef2 mutant backgrounds to create the following lines: $D f(2 R) P 520 / C y O, P\left[w^{+} l a c Z\right]$; UAS-mef2/UAS-mef2 and mef2 $\left.22 \cdot 21 / C y O, P / w^{+} l a c Z\right) ; 24 B / 24 B$. These line were crossed to generate progeny in which $100 \%$ carried one copy each of the 24B source of GAL4 and the UASmef 2 construct. Of these progeny, $75 \%$ carried at least one copy of a $\mathrm{CyO}$ balancer that directed expression of $\beta$-gal activity. The source of MEF2 protein in the mutant progeny, which lack $\beta$-gal expression was the transgene.

\section{Molecular biology techniques}

The cosmid and $\lambda$ genomic clones presented here were derived from a genomic walk in the region surrounding the FMRFamide gene (O'Brien et al. 1994). The structural organization of the mef2 gene was determined by Southern blotting analysis of restriction digests of various cosmid and $\lambda$ genomic clones, using labeled fragments corresponding to different regions of the mef2 DNA under standard conditions (Sambrook et al. 1989). Targeted sequencing of the mef2 gene was done by use of specific primers corresponding to various regions of the gene, and an automated sequencing system.

Genomic DNA was isolated from homozygous mutant embryos from the EMS allele mef2 $22-21$, as described previously (Bodmer 1993). Specific primers were used in PCR to amplify the fragments spanning the second and third exons, as well as the second intron. The primers, with nucleotide sequences of $5^{\prime}$-CCTGGGGACAATTTATACGG-3' and 5'-TAGCCATGAATCGATTCACC-3' and the set of primers with nucleotide sequences of 5'-CCTTCAACAAGCGCAAGTTC- ${ }^{\prime}$ and $5^{\prime}$ CGATGATGTTCTTGTTGGTG-3' were used to obtain the second and third exon, respectively. The primers with the sequences of $5^{\prime}$-CACGCATCACCGATGAACGC- 3 ' and 5'-CTTCATCACGCCGAACTTGC-3' were used to amplify the second intron. Three independent PCR reactions were performed for each set of primers. The PCR-generated fragments were then subcloned in to the pCRII vector (InVitrogen, CA) and sequenced by use of an automated sequencing system. Three different subclones from each PCR reaction of homozygous mutant DNA were analyzed.

\section{$\beta$-Gal staining}

$\beta$-Gal activity was used to distinguish phenotypic wild-type from homozygous mutant embryos, which were identified by the absence of $\beta$-gal activity.

The $\beta$-gal staining procedure was obtained from Drs. A. Singh and M. Kango (Drosophila Stock Center, India). Embryos were dechorionated in $50 \%$ bleach and fixed in $4 \%$ paraformaldehyde in citric phosphate buffer (CPB: $90 \mathrm{mM} \mathrm{Na} \mathrm{HPO}_{4}, 5 \mathrm{~mm}$ citric acid at $\mathrm{pH} 7.6$ ) and $50 \%$ ( $\mathrm{vol} / \mathrm{vol}$ ) heptane. The fixative was removed, and the embryos were washed in CPB in the presence of heptane. The embryos were then air-dried and transferred to a solution consisting of $5 \mathrm{~mm}$ potassium ferricyanide, $5 \mathrm{~mm}$ potassium ferrocyanide, and $0.5 \%$ Triton X-100, prewarmed at $65^{\circ} \mathrm{C}$. The substrate $\mathrm{X}$-gal was added to $0.1 \%$, and the embryos were incubated in this solution for $24-48 \mathrm{hr}$ at $37^{\circ} \mathrm{C}$. Stained embryos were refixed in $4 \%$ formaldehyde, $50 \mathrm{~mm}$ EGTA and $50 \%(\mathrm{vol} / \mathrm{vol})$ heptane. Following washes in heptane, an equal volume of $5 \%$ TCA was added and the embryos were shaken for $2 \mathrm{~min}$ and then allowed to stand for $5 \mathrm{~min}$. After additional washes in heptane, the embryos were devitellinized in an equal volume of $90 \%$ methanol, $5 \mathrm{~mm}$ EGTA. Subsequent immunocytochemistry with a specific antibody was performed, as described below.

\section{Antibodies and immunocytochemistry}

Polyclonal anti-MEF2 antibodies were generated by injecting a GEX2T-MEF2 fusion protein (amino acids 1-168) into New Zealand white rabbits by use of standard conditions. The various antibodies discussed herein were used at the following dilutions: anti-MEF2 (1:800) with preabsorption with wild-type 
embryos, anti-NAU (1:25), anti- $\beta 3$-Tubulin $(1: 250)$ (Leiss et al. 1988), anti-MHC (1:1000) (D. Kiehart, unpubl.), anti-EVE (1:5000) (Frasch et al. 1987), and a monoclonal recognizing a cell-surface protein that is expressed on pericardial cells $(1: 10)$ (T. Volk, unpubl.).

Embryos were collected on agar/apple juice plates at 0- to 6-hr intervals and aged an additional 6 or $12 \mathrm{hr}$ at $25^{\circ} \mathrm{C}$, as appropriate. For double antibody stainings, in which a specific antibody and a $\beta$-gal antibody (Sigma) were used, the embryos were dechorionated in $50 \%$ bleach and fixed in $4 \%$ formaldehyde in 0.1 M HEPES (pH 7), $1 \mathrm{~mm}$ EGTA, $2 \mathrm{~mm} \mathrm{MgSO}_{4}$, and 50\% (vol/vol) heptane. Subsequent immunocytochemistry with all specific antibodies was performed essentially as described (Ashburner 1989|. Detection of the biotinylated secondary antibody was performed by use of the Vectastain $\mathrm{ABC}$ kit /Vector Laboratories, $\mathrm{CA}$ ) for $\mathrm{MHC}$ and $\beta 3$-Tubulin antibodies or the Vectastain Elite ABC kit (Vector Laboratories, CA) for MEF2, EVE, NAU, and pericardial cell-surface protein antibodies, according to manufacturer's instructions.

\section{Cell death assay}

Acridine orange staining was done as described in Abrams et al. (1993). Mutant embryos were identified on the basis of their abnormal gut morphology. The embryos were photographed with Normarski transillumination.

\section{Acknowledgments}

We thank S. Treadway and A.E. Stephenson for complementation analysis, M. Grill for technical assistance, D. Kiehart, M. Frasch, R. Renkawitz-Pohl, and T. Volk for generous gifts of antibodies, $\mathrm{H}$. Bellen and N. Perrimon for fly strains, and $\mathrm{M}$. Frasch for critical reading of the manuscript. This work was supported by grants from the American Heart Association-Massachusetts Affiliate (H.T.N.), American Heart Association (R.B.), Del E. Webb Foundation (E.S.G.), March of Dimes (S.M.A.), Muscular Dystrophy Association (R.B.), National Institutes of Health (E.S.G., P.H.T), and National Science Foundation (P.H.T). S.M.A. is the recipient of a Junior Faculty Award from the American Cancer Society.

The publication costs of this article were defrayed in part by payment of page charges. This article must therefore be hereby marked "advertisement" in accordance with 18 USC section 1734 solely to indicate this fact.

\section{Note added in proof}

The phenotype of a D-mef2 deficiency was reported recently by Lilly et al. (1995) in Science 267: 688-693.

\section{References}

Abrams, J.M., K. White, L.I. Fessler, and H. Steller. 1993. Programmed cell death during Drosophila embryogenesis. Development 117: 29-43.

Ashburner, M. 1989. Drosophila: A laboratory manual. Cold Spring Harbor Laboratory Press, Cold Spring Harbor, New York.

Azpiazu, N. and M. Frasch. 1993. tinman and bagpipe: Two homeo box genes that determine cell fates in the dorsal mesoderm of Drosophila. Genes \& Dev. 7: 1325-1340.

Barad, M., A. Erlebacher, and W. McGinnis. 1991. Despite expression in embryonic visceral mesoderm, H2.0, is not essential for Drosophila visceral muscle morphogenesis. Dev. Genet. 12: 206-211.

Bate, M. 1990. The embryonic development of larval muscles in Drosophila. Development 110: 791-804.
Bate, M., E. Rushton, and M. Frasch. 1993. A dual requirement for neurogenic genes in Drosophila myogenesis. Development (Suppl.) 149-161.

Bernstein, S.I., P.T. O'Donnell, and R.M. Cripps. 1993. Molecular genetic analysis of muscle development, structure, and function in Drosophila. Intl. Rev. Cytol. 143: 63-152.

Bodmer, R. 1993. The gene tinman is required for specification of the heart and visceral muscles in Drosophila. Development 118: 719-729.

Bonini, N.M., W.M. Leiserson, and S. Benzer. 1993. The eyes absent gene: Genetic control of cell survival and differentiation in the developing Drosophila eye. Cell 72: 379-395.

Bourgouin, C., S.E. Lundgren, and J.B. Thomas. 1992. apterous is a Drosophila LIM domain gene required for the development of a subset of embryonic muscles. Neuron 9: 549-561.

Brand, A.H and N. Perrimon. 1993. Targeted gene expression as a means of altering cell fates and generating dominant phenotypes. Development 118: 401-415.

Braun, T., M.A. Rudnicki, H.-H. Arnold, and R. Jaenisch. 1992. Targeted inactivation of the muscle regulatory gene Myf-5 results in abnormal rib development and perinatal death. Cell 71: 369-382.

Campos-Ortega, J.A. and V. Hartenstein. 1985. The embryonic development of Drosophila melanogaster. Springer-Verlag, Berlin, Germany.

Cheng, T.-C., M. Wallace, J.P. Merlie, and E.N. Olson. 1993. Separable regulatory elements govern myogenin transcription in somites and limb buds. Science 261: 215-218.

Cserjesi, P. and E.N. Olson. 1991. Myogenin induces the muscle-specific enhancer binding factor MEF- 2 independently of other muscle-specific gene products. Mol. Cell. Biol. 11: 4854-4862.

Dohrmann, C., N. Azpiazu, and M. Frasch. 1990. A new Drosophila homeo box gene is expressed in mesodermal precursor cells of distinct muscles during embryogenesis. Genes \& Dev. 4: 2098-2111.

Edmonson, D.G., T.C. Cheng, P. Cserjesi, T. Chakraborty, and E.N. Olson. 1992. Analysis of the myogenin promoter reveals an indirect pathway for positive autoregulation mediated by MEF2. Mol. Cell. Biol. 12: 3665-3667.

Edmonson, D.G., G.E. Lyons, J.F. Martin, and E.N. Olson. 1994. Mef2 gene expression marks the cardiac and skeletal muscle lineages during mouse embryogenesis. Development 120: 1251-1263.

Frasch, M., T. Hoey, C. Rushlow, H. Doyle, and M. Levine. 1987. Characterization and localization of the Even-Skipped protein of Drosophila. EMBO I. 6: 749-759.

Funk, W.D. and W.E. Wright. 1992. Cyclic amplification and selection of targets for multicomponent complexes: Myogenin interacts with factors recognizing binding sites for basic helix-loop-helix, nuclear factor 1, myocyte-specific enhancer factor 2, and COMP1 factor. Proc. Natl. Acad. Sci. 89: 9484 9488.

Gossett, L.A., D.J. Kelvin, E.A. Sternberg, and E.N. Olson. 1989. A new myocyte-specific enhancer-binding factor that recognizes a conserved element associated with multiple musclespecific genes. Mol. Cell. Biol. 9: 5022-5033.

Hasty, P., A. Bradley, J.H. Morris, D.G. Edmonson, J.M. Venuti, E.N. Olson, and W.H. Klein. 1993. Muscle deficiency and neonatal death in mice with a targeted mutation in the myogenin gene. Nature 364: 501-506.

Kassis, J.A., E. Noll, E.P. VanSickle, W.F. Odenwald, and N. Perrimon. 1992. Altering the insertional specificity of a Drosophila transposable elment. Proc. Natl. Acad. Sci. 89: 1919-1923.

Kaushal, S., J.W. Schneider, B. Nadal-Ginard, and V. Mahdavi. 
1994. Activation of the myogenic lineage by MEF2A, a factor that induces and cooperates with MyoD. Science 266: 12361240.

Kosman, D., Y.T. Ip, M. Levine, and K. Arora. 1991. Establishment of the mesoderm-neuroectoderm boundary in the Drosophila embryo. Nature 254: 118-122.

Lai, Z., E. Rushton, M. Bate, and G.M. Rubin. 1993. Loss of function of the Drosophila $z$ fh-1 gene results in abnormal development of mesodermally derived tissues. Proc. Natl. Acad. Sci. 90: 4122-4126.

Lassar, A. and A. Munsterberg. 1994. Wiring diagrams: Regulatory circuits and the control of skeletal myogenesis. Curr. Opin. Cell. Biol. 6: 432-442.

Leiss, D., U. Hinz, A. Gasch, R. Mertz, and R. Renkawitz-Pohl. 1988. $\beta 3$-Tubulin expression characterizes the differentiating layer during Drosophila embryogenesis. Development 104: 525-531.

Lilly, B., S. Galewsky, A.B. Firulli, R.A. Schulz, and E.N. Olson. 1994. D-MEF2: A MADS box transcription factor expressed in differentiating mesoderm and muscle cell lineages during Drosophila embryogenesis. Proc. Natl. Acad. Sci. 91: 56625666.

Luo, L., Y.J. Liao, L.Y. Jan, and Y.-N. Jan. 1994. Distinct morphogenetic functions of similar small GTPases: Drosophila Drac1 is involved in axonal outgrowth and myoblast fusion. Genes \& Dev. 8: 1781-1802.

Martin, J.F., J.J. Schwarz, and E.N. Olson. 1993. Myocyte enhancer factor (MEF)2C: A tissue-restricted member of the MEF-2 family of transcription factors. Proc. Natl. Acad. Sci. 90: 5282-5286.

Michelson, A.M., S.M. Abmayr, M. Bate, A. Martinez-Arias, and T. Maniatis. 1990. Expression of a MyoD family member prefigures muscle pattern in Drosophila embryos. Genes 4$)$ Dev. 4: 2086-2097.

Nabeshima, Y., K. Hanaoka, M. Hayasaka, E. Esumi, S. Li, I. Nonaka, and Y. Nabeshima. 1993. Myogenin gene disruption results in perinatal lethality because of severe muscle defects. Nature 364: 532-535.

Nakatsuji, Y., K. Hidaka, S. Tsujino, Y. Yamamoto, T. Mukai, T. Yanagihara, T. Kishimoto, and S. Sakoda. 1992. A single MEF2 site is a major positive regulatory element required for transcription of the muscle-specific subunit of the human phosphoglycerate gene in skeletal and cardial muscle cells. Mol. Cell. Biol. 12: 4384-4390.

Navankasttusas, S., H. Zhu, A.V. Garcia, S.M. Evans, and K.R. Chien. 1992. A ubiquitous factor (HF-la) and a distinct muscle factor (HF-1b/MEF2) form an E-box independent pathway for cardiac muscle gene expression. Mol. Cell. Biol. 12: $1469-1479$.

Nguyen, H.T., R.B. Bodmer, S.M. Abmayr, J.C. McDermott, and N.A. Spoerel. 1994. D-mef2: A Drosophila mesoderm-specific MADS box containing gene with a biphasic expression profile during embryogenesis. Proc. Natl. Acad. Sci. 91: 7520-7524.

O'Brien, M.A., M.S. Roberts, and P.H. Taghert. 1994. A genetic and molecular analysis of the $46 \mathrm{C}$ chromosomal region surrounding the FMRFamide neuropeptide gene in Drosophila melanogaster. Genetics 137: 121-137.

Olson, E.N. and W.H. Klein. 1994. bHLH factors in muscle development: Dead lines and commitments, what to leave in, and what to leave out. Genes \& Dev. 8: 1-8.

Patel, N., P.M. Snow, and C.S. Goodman. 1987. Characterization and cloning of fasciclin III: A glycoprotein expressed on a subset of neurons and axon pathways in Drosophila. Cell 48: $975-988$.

Paterson, B.M., U. Walldorf, J. Elridge, A. Dubendorfer, M.
Frasch, and W.J. Gehring. 1991. The Drosophila homologue of vertebrate myogenic-determination genes encodes a transiently-expressed nuclear protein marking primary myogenic cells. Proc. Natl. Acad. Sci. 88: 3782-3786.

Reuter, R. and M.P. Scott. 1990. Expression and function of the homoeotic genes Antennapedia and Sex combs reduced in the embryonic midgut of Drosophila. Development 109: 289-303.

Roth, S., D. Stein, and C. Nüsslein-Volhard. 1989. A gradient of nuclear localization of the Dorsal protein determines dorsoventral pattern in the Drosophila embryo. Cell 59: 11891202.

Rubin, G.M. and A.C. Spradling. 1982. Genetic transformation of Drosophila with transposable element vectors. Science 218: 348-353.

Rudnicki, M.A., T. Braun, S. Hinuma, and R. Jaenisch. 1992. Inactivation of MyoD in mice leads to upregulation of the myogenic HLH gene Myf-5 and results in apparently normal muscle development. Cell 71: 383-390.

Rudnicki, M.A., P.N.J. Schnegelsberg, R.H. Stead, T. Braun, H.-H. Arnold, and R. Jaenisch. 1993. MyoD or Myf-5 is required for the formation of skeletal muscle. Cell 75: 13511359.

Rushlow, C., K. Han, J.L. Manley, and M. Levine. 1989. The graded distribution of the Dorsal morphogen is initiated by selective nuclear transport in Drosophila. Cell 59: 11651177.

Sambrook, J., E.F. Fritsch, and T. Maniatis. 1989. Molecular cloning: A laboratory manual, 2nd ed. Cold Spring Harbor Laboratory Press, Cold Spring Harbor, New York.

Shishido, E., S.-I. Higashijima, Y. Emori, and K. Saigo. 1993. Two FGF-receptor homologues of Drosophila: One is expressed in mesodermal primordium in early embryos. Development 117: 751-761.

Smouse, D. and N. Perrimon. 1990. Genetic dissection of a complex neurological mutant, polyhomeotic, in Drosophila. Dev. Biol. 139: 169-185.

Spradling, A.C. and G.M. Rubin. 1982. Transposition of cloned P elements into Drosophila germ line chromosomes. Science 218: 341-347.

Steward, R. 1989. Relocalization of the Dorsal protein from the cytoplasm to the nucleus correlates with its function. Cell 59: 1179-1188.

Tapscott, S.J., A.B. Lassar, and H. Weintraub. 1992. A novel myoblast enhancer element mediates $\mathrm{MyoD}$ transcription. Mol. Cell. Biol. 12: 4994-5003.

Tepass, U., C. Theres, and E. Knust. 1990. crumbs encodes an EGF-like protein expressed on apical membranes of Drosophila epithelial cells and required for organization of epithelia. Cell 61: 787-799.

Weintraub, H. 1993. The MyoD family and myogenesis: Redundancy, networks, and thresholds. Cell 75: 1241-1244.

Wentworth, B.M., M. Donohue, J.C. Engert, E.B. Berglund, and N. Rosenthal. 1991. Paired myoD binding sites regulate myosin light chain gene expression. Proc. Natl. Acad. Sci. 88: 1242-1246.

White, K., M.E. Grether, J.M. Abrams, L. Young, K. Farrell, and H. Steller. 1994. Genetic control of programmed cell death in Drosophila. Science 264: 677-683.

Yee, S.-P. and W.J. Rigby. 1993. The regulation of myogenin gene expression during the embryonic development of the mouse. Genes \& Dev. 7: 1277-1289. 


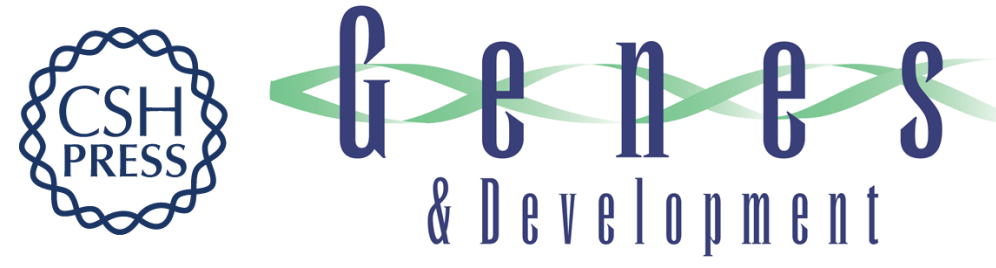

\section{Drosophila MEF2, a transcription factor that is essential for myogenesis.}

B A Bour, M A O'Brien, W L Lockwood, et al.

Genes Dev. 1995, 9:

Access the most recent version at doi:10.1101/gad.9.6.730

References This article cites 53 articles, 32 of which can be accessed free at:

http://genesdev.cshlp.org/content/9/6/730.full.html\#ref-list-1

License

Email Alerting

Service

Receive free email alerts when new articles cite this article - sign up in the box at the top right corner of the article or click here.

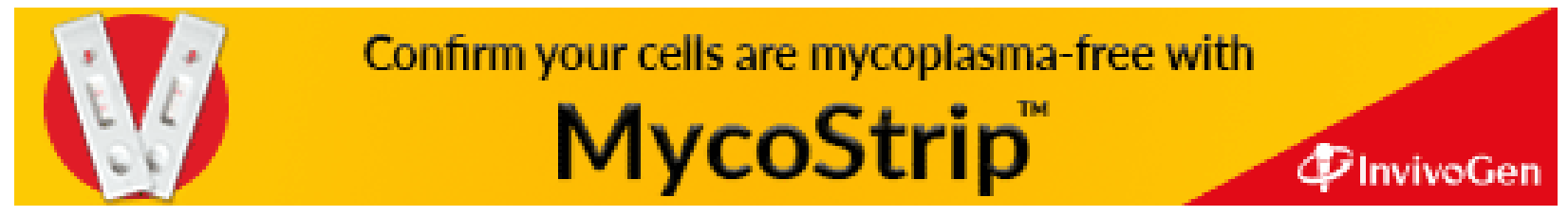

